\title{
O ensino de Estatística apresentado nos materiais curriculares dos três primeiros anos do Ensino Fundamental
}

\section{The teaching of Statistics presented in the curricular materials of the first three years of Elementary School}

\author{
Priscila Bernardo Martins \\ Suzete de Souza Borelli \\ Edda Curi
}

\begin{abstract}
Resumo: 0 presente estudo tem por objetivo analisar se as atividades propostas no material curricular de Matemática, denominado Caderno do Aluno, do projeto Educação Matemática nos Anos Iniciais (EMAI), dos três primeiros anos do Ensino Fundamental, empregado pela Rede Estadual de Ensino de São Paulo, permitem o desenvolvimento da Literacia Estatística dos estudantes. Assim, optou-se pela análise documental na perspectiva de Bardin (2016). Como resultados, foi possível observar que as atividades analisadas contribuem para a promoção do desenvolvimento da Literacia Estatística, por encaminhar os estudantes na compreensão das informações estatísticas, na organização dos dados e na representação de tabelas. Contudo, observou-se que a aquisição da Literacia Estatística requer outras habilidades que as atividades não incentivam tanto - a capacidade de argumentar, a construção e representação de gráficos e tabelas, a apropriação do vocabulário estatístico e a competência de produzir textos acerca de suas interpretações.
\end{abstract}

Palavras-chave: Literacia Estatística. Ensino de Matemática. Anos Iniciais do Ensino Fundamental.

Abstract: The present study aims to analyze whether the activities proposed in the Mathematics curriculum materials, called Caderno do Aluno, Educação Matemática nos Anos Iniciais (EMAI) project, from the first three years of Elementary School, employed by the State Education Network of São Paulo, allow the development of Literacy Student statistics. Thus, we opted for documentary analysis from the perspective of Bardin (2016). As a result, it was possible to observe that the analyzed activities contribute to the promotion of the development of Statistical Literacy, by guiding students in understanding statistical information, organizing data and representing tables. However, it was observed that the acquisition of Statistical Literacy requires other skills that the activities do not encourage as much - the ability to argue, the construction and representation of graphs and tables, the appropriation of statistical vocabulary and the competence to produce texts about their interpretations.

Keywords: Statistical Literacy. Mathematics Teaching. Early Years of Elementary School.
Priscila Bernardo Martins Doutora em Ensino de Ciências e Matemática. Professora da Universidade Cruzeiro do Sul (Unicsul). São Paulo, Brasil

iD orcid.org/0000-0001-6482-4031

$\bowtie$ priscila.bmartins11@gmail.com

Suzete de Souza Borell Doutora em Ensino de Ciências e Matemática. Professora da Secretaria Municipal de Educação de São Paulo (SMESP). São Paulo, Brasil. orcid.org/0000-0002-0738-8162

$\bowtie$ suzeteborelli@gmail.com

Edda Curi

Doutora em Educação Matemática. Professora do Programa de Pós-Graduação em Ensino de Ciências e Matemática da Universidade Cruzeiro do Sul (Unicsul). São Paulo, Brasil

iD orcid.org/0000-0001-6347-0251 $\bowtie$ edda.curi@gmail.com

Recebido em 22/07/2020 Aceito em 21/09/2020 Publicado em 09/11/2020 


\section{Introdução}

Atualmente, o conhecimento estatístico é considerado primordial e demanda a necessidade social para ler e compreender as variadas fontes de informações veiculadas pelos diferentes meios de comunicação. Nesse sentido, essas informações podem ser preponderantes para persuadir as tomadas de decisões e requer uma análise crítica dos fatos.

Na Educação Matemática, a relevância que a Estatística desempenha decorre do fato de se tratar de um campo de conhecimento que requer ampla participação do indivíduo em sociedade, em exercício de cidadania. Para isso, é importante a discussão sobre o conceito de literacia discutido por Batanero, Arteaga e Contreras (2011), Gal (2002), Lopes (2004) e DelMas (2002).

De acordo com Lopes (2008), a escola, desde os primeiros anos de escolaridade, deve oferecer ao estudante uma formação de conceitos que contribuam no exercício de sua cidadania. Concordamos com essa autora, pois acreditamos que é improtelável que a escola exerça o seu papel de educar para a cidadania, que inclui formar cidadãos capazes de ler, compreender, ponderar, criticar e argumentar para dar sentido à informação estatística.

As orientações sobre o ensino de Estatística foram inseridas oficialmente nos Parâmetros Curriculares Nacionais de Matemática para o Ensino Fundamental (PCN) em 1997, organizadas no bloco de conteúdo denominado Tratamento da Informação. Nesse documento, o propósito foi o de fazer com que o estudante pudesse construir métodos para coletar, organizar, comunicar e interpretar dados, empregando tabelas, gráficos e representações que surgem usualmente no seu cotidiano.

Com a proposta da Base Nacional Comum Curricular (BNCC 1 ) relativa ao ensino de Matemática, a abordagem da Estatística nos Anos Iniciais deve ser voltada para a coleta e a organização de dados de uma pesquisa de interesse comum dos estudantes. 0 documento destaca que o planejamento de como fazer a pesquisa contribui para a compreensão do papel que a Estatística exerce no cotidiano dos estudantes. O documento aponta, ainda, sobre a relevância da leitura, da interpretação e da construção de tabelas e gráficos, assim como o modo de produção de texto para a comunicação de dados (BRASIL, 2017).

\footnotetext{
1 Documento normativo que indica os Objetos de Conhecimento e as Habilidades que devem ser construídas ao longo do Ensino Fundamental, incluindo o Ensino de Estatística. Também orienta às instâncias estaduais e municipais na organização de seus currículos a partir dos contextos e experiências vivenciadas, de modo a nortear a prática pedagógica do professor em sala de aula.
} 
Batanero, Arteaga e Contreras (2011) chamam atenção para o fato que, muito embora a Estatística esteja inserida no currículo prescrito, em todos os níveis de ensino, concebendo-a como um recurso importante tanto na vida pessoal, quanto profissional, há estudos que apontam que muitos estudantes, mesmo no nível Superior de Ensino, não são aptos a fazer uma interpretação adequada dos dados estatísticos.

Desse modo, este artigo tem por objetivo analisar as propostas de atividades dos três primeiros anos do Ensino Fundamental, envolvendo o ensino de gráficos e tabelas no material curricular empregado pela Rede Estadual de Ensino de São Paulo. Especificamente, buscamos averiguar se as atividades propostas possibilitam o desenvolvimento da Literacia Estatística.

\section{Literacia Estatística}

No dicionário online de Português - DICIO, o termo literacia é tratado como a capacidade de ler, de escrever, de compreender e de interpretar o que é lido; letramento.

Batanero, Arteaga e Contreras (2011) evidenciam que o termo literacia estatística surgiu instintivamente, nos últimos anos, entre educadores estatísticos, pois esses consideram o fato de que a Estatística é reconhecida como parte do patrimônio cultural essencial para o cidadão educado.

Autores como Gal (2002) definem a Literacia Estatística como dois aspectos correlatos: (1) a capacidade dos indivíduos de interpretar e analisar criticamente os dados estatísticos, referentes aos argumentos ou fenômenos que são possíveis de identificar em diferentes contextos; (2) a capacidade de discutir ou comunicar as informações estatísticas, ou seja, a compreensão do significado da informação, suas convicções sobre os encadeamentos dessas informações e os cuidados com relação à aceitabilidade de considerações fornecidas.

O autor propõe um modelo dinâmico de Literacia Estatística que envolve os dois aspectos citados: conhecimentos cognitivo e afetivo, conforme destacado no Quadro 1.

Para Gal (2002), as habilidades em Literacia dizem respeito à situação dos indivíduos desenvolver competências para compreender informações denotadas em formato de pequenos textos contendo dados estatísticos. Essa habilidade requer que os indivíduos saibam dar sentido às informações em variados níveis de complexidade. Já os conhecimentos estatísticos referemse à compreensão dos significados concedidos aos números no contexto; no entendimento das 
variáveis e sua natureza; na interpretação de tabelas e gráficos; compreender e realizar as etapas da pesquisa, incorporando procedimento de coleta e análise de dados.

Quadro 1: Modelo proposto sobre Literacia Estatística

\begin{tabular}{|c|c|}
\hline \multicolumn{2}{|c|}{ LITERACIA ESTATísTICA } \\
\hline Aspecto Cognitivo & Aspecto Afetivo \\
\hline Habilidades em literacia & Crenças e atitudes \\
Conhecimentos Estatísticos & Postura Crítica \\
Conhecimentos Matemáticos & \\
Conhecimentos Contextuais & \\
Questionamentos Críticos & \\
\hline
\end{tabular}

Fonte: Gal (2002, p. 4)

Quanto aos conhecimentos matemáticos, para Gal (2002), há uma relação entre a Matemática e a Estatística na abordagem de alguns conteúdos: médias, frações, números decimais, entre outros. No que tange ao conhecimento do contexto, o propósito é que os indivíduos desenvolvam competências estatísticas no emprego das informações no contexto que estão inseridos, envolvendo indivíduo e mundo real. Os questionamentos críticos, segundo o autor, condizem com a análise crítica da informação, para validar a natureza da informação recebida.

O segundo aspecto, Gal (2002) indica que contempla o domínio afetivo, trata de duas questões. Nas crenças e atitudes, a ação é por meio de princípios e convicções sobre a sociedade, sobre si mesmo e sobre o contexto. 0 propósito é possibilitar base para que os indivíduos desenvolvam crenças e atitudes na validação da conduta crítica. Na postura crítica, o indivíduo deve ter atitude de questionamento frente às informações estatísticas.

Lopes (2004), em seus estudos, afirmou que a Literacia Estatística requer que o indivíduo tenha a habilidade de ler e interpretar tabelas e gráficos, compreender as medidas de posição e dispersão, empregar as ideias de aleatoriedade, chance e probabilidade para tomar decisões sobre eventos volúveis e confrontar a amostra com a população. Para essa pesquisadora, "isso é muito mais do que possuir competências de cálculo, é preciso adquirir habilidades para compreender a leitura e a interpretação numérica necessária para o exercício pleno da cidadania com responsabilidade social na tomada de decisões" (LOPES, 2004, p. 187-188).

DelMas (2002) analisou as convergências e divergências das pesquisas de Deb Rumsey, Joan Garfield e Beth Chance acerca das similaridades e diferenças entre os termos Literacia 
Estatística, raciocínio e pensamento. Ele pondera que alguns autores evidenciam a Literacia Estatística como o desenvolvimento de competências primordiais ao desenvolvimento do raciocínio e pensamento estatístico. Outros evidenciam que raciocínio e o pensamento estatístico estão compreendidos no domínio da Literacia Estatística, apresentando a perspectiva de Literacia como um conceito mais abrangente da Estatística.

Concordamos com DelMas (2002) ao afirmar que a diferenciação entre esses termos não decorre dos conteúdos que estão alusivos com cada um deles, mas sim de relacionar cada um desses domínios ao que é proposto aos estudantes em uma situação de ensino. 0 autor propõe - Quadro 2, a seguir, que relaciona as tarefas que podem diferenciar os três domínios.

Quadro 2: Tarefas que podem distinguir os três domínios instrucionais

\begin{tabular}{|c|c|c|}
\hline Literacia Estatística & Raciocínio Estatístico & Pensamento Estatístico \\
\hline $\begin{array}{c}\text { Identificar, descrever; } \\
\text { reformular, traduzir, } \\
\text { interpretar e ler. }\end{array}$ & $\begin{array}{c}\text { Por quê? Como? Esclareça } \\
\text { o processo. }\end{array}$ & Aplicar, criticar e generalizar \\
\hline
\end{tabular}

Fonte: Del Mas (2002, p. 4)

Alguns autores como Jacobini et al. (2010) trazem uma diferenciação entre os termos raciocínio estatístico e pensamento estatístico. Para esses autores, o raciocínio estatístico engloba a interpretação e a representação de dados em gráficos e tabelas. Já o pensamento estatístico exterioriza-se quando os estudantes percebem que os resultados de uma pesquisa estatística indicam uma tendência e não uma certeza, interpretam os resultados e os exploram sob variadas perspectivas.

Há ainda o entendimento que o raciocínio é circunscrito apenas à produção de pensamento consciente, exemplificando como o emprego da lógica. Já o pensamento nem sempre é lógico e consciente (CURI, 2019).

Diante das definições apresentadas nessa seção, assumimos a perspectiva de DelMas (2002) que considera a Literacia Estatística como um conceito mais amplo e que incorpora 0 raciocínio e pensamento estatístico como domínios, pois compreendemos que antes de um indivíduo ser capaz de ler, interpretar e analisar criticamente os dados estatísticos e de discutir acerca das informações estatísticas (Literacia Estatística), requer a compreensão das informações disponíveis (Raciocínio) e a sua conclusão a respeito dessas informações (Pensamento). 


\section{0 ensino de Gráficos e Tabelas}

No campo da Educação Matemática é crescente a preocupação de muitos pesquisadores com relação à leitura e interpretação de dados representados graficamente, uma vez que a pluralidade de informações é indispensável na sociedade atual. Assim, a construção de gráficos e tabelas e o engajamento dos estudantes em investigações de campo tornou-se uma opção metodológica que permite a compreensão da concepção do número em situações expressivas (FLORES e MORETTI, 2005).

De acordo com Flores e Moretti (2005), a leitura e a interpretação de gráficos e tabelas é considerada por muitos como algo relativamente simples, em virtude de sua organização e a agilidade de consulta. Contudo, segundo os autores, não é uma tarefa imediata, pois a leitura requer proximidade, por parte do leitor, como também domínio na representação empregada - saber ler, interpretar, analisar, pressupor e organizar os dados em gráficos e tabelas exige a competência do próprio funcionamento representacional.

Flores e Moretti (2005) chamam a atenção para as representações gráficas do tipo tabela, pois é necessário considerar que elas detêm de algumas vantagens, por permitir a visualização dos dados de modo independente, integrando a função cognitiva de identificação. Para os autores, analisar a contribuição cognitiva das tabelas, e seus múltiplos empregos, requer reconhecer dois aspectos: a organização representacional e as funções cognitivas que elas complementam. Para Flores e Moretti (2005), a organização representacional das tabelas é perceptível à ordenação dos dados, em linhas e em colunas. Contudo, tal característica não é exclusiva das tabelas e não é o bastante para caracterizar o funcionamento representacional das tabelas, pois requer particularizar a especificidade das tabelas em correlação as outras representações gráficas.

A complexidade na interpretação de gráficos foi discutida nos estudos de Curcio (1987, 1989). O pesquisador propõe que os estudantes da escola básica devem ser envolvidos, de forma gradativa, na coleta de dados do cotidiano, objetivando construir seus próprios gráficos. Desse modo, haveria incentivo para o levantamento de hipóteses e verbalizações das relações e dos padrões observados nos dados coletados, por exemplo: "maior que", "duas vezes maior que".

Em seus estudos, Curcio $(1987,1989)$ retratou a complexidade na interpretação de gráficos. Para o autor, os gráficos podem ser observados como um tipo de texto, cuja leitura pode ser categorizada em três níveis: leitura de dados, leitura entre os dados e leitura além dos dados.

A leitura de dados, no primeiro nível, é feita de modo literal, não se realiza uma 
interpretação. Em se tratando da leitura entre os dados, este segundo nível requer a interpretação dos dados do gráfico. 0 estudante, nesse nível, deve fazer uma combinação e integração de informações, além de reconhecer relações matemáticas a partir de conhecimento prévio sobre a temática tratada no gráfico. Quanto ao terceiro nível, denominado leitura além dos dados, o estudante deve fazer previsões e inferências a partir dos dados sobre informações que não estão implícitas no gráfico. 0 avanço entre esses níveis desenrola-se a partir da exploração dos gráficos em sala de aula.

A pesquisadora Kemp (2005) propõe um modelo (Quadro 3) para apoiar os professores no seu planejamento, de modo que possa contribuir para que os estudantes desenvolvam níveis de pensamento, buscando tendências e significados. Para Kemp (2005), as cinco etapas fornecem apoio aos estudantes para desenvolver estratégias para a interpretação de dados, representados em forma de tabela (simples ou complexa) e gráficos.

Quadro 4: Estrutura de cinco etapas para interpretação de tabelas e gráficos

\begin{tabular}{|c|l|}
\hline Etapa 1 - Como iniciar? & $\begin{array}{l}\text { Observar o título, eixos, especificadores, legendas, notas de } \\
\text { rodapé e fonte para descobrir o contexto, a qualidade e a } \\
\text { fidelidade dos dados. }\end{array}$ \\
\hline $\begin{array}{c}\text { Etapa } 2 \text { - O que os números } \\
\text { expressam? }\end{array}$ & $\begin{array}{l}\text { Certificar a compreensão de todos os números representados } \\
\text { (percentagens, entre outros). }\end{array}$ \\
\hline Etapa 3 - Como diferem? & $\begin{array}{l}\text { Compreender as diferenças nos valores dos dados no } \\
\text { conjunto de dados, uma linha ou coluna ou parte de um } \\
\text { gráfico. Tais diferenças podem incluir alterações a longo } \\
\text { prazo, ou a comparação dentro de uma determinada } \\
\text { categoria }\end{array}$ \\
\hline Etapa $4-$ Quais as diferenças? & $\begin{array}{l}\text { Localizar as relações da tabela ou gráfico que unem às } \\
\text { variáveis. Empregar informações da etapa 3 para apoiar a } \\
\text { tecer comparações entre duas ou mais categorias. }\end{array}$ \\
\hline Etapa $5-$ Por que os valores se & $\begin{array}{l}\text { Compreender o motivo das diferenças e das relações dos } \\
\text { dados, considerando fatores sociais, políticos, ambientais e } \\
\text { econômicos. }\end{array}$ \\
\hline
\end{tabular}

Fonte: $\operatorname{Kemp}(2005$, p. 3)

\section{Pressupostos Metodológicos}

O referido estudo é de natureza qualitativa. Assim, para proceder com o processo analítico das atividades, nos apoiaremos na análise documental, na perspectiva de Bardin (2016), que 
afirma tratar-se de um procedimento ou conjunto de procedimentos, tencionando representar 0 conteúdo presente em um documento sob uma forma diferente proveniente do original, com 0 intuito de simplificar, na sequência, a sua consulta e referência.

Com a perspectiva de análise documental, foram averiguados o documento e material empregado na Rede Estadual de Ensino de São Paulo. O documento denominado Currículo Paulista está situado na instância de currículo prescrito proposto por Sacristán (2013). 0 documento curricular denominado Currículo Paulista, de Matemática, abrange as competências gerais especificadas na BNCC (BRASIL, 2017). O documento determina e evidencia as habilidades fundamentais para o desenvolvimento cognitivo, social e emocional dos estudantes, levando em conta a sua formação integral.

Quanto ao material curricular intitulado EMAI \& Ler e Escrever - Ensino Fundamental, $v$ 1, apresenta-se alocado na instância do currículo apresentado (SACRISTAN, 2013). Cabe destacar que esse material foi organizado à luz do Currículo Paulista e foi divido em duas partes. Desse modo, as nossas análises serão centradas na parte denominada EMAl - Educação Matemática nos Anos Iniciais do Ensino Fundamental.

O Caderno do Aluno apresenta atividades em forma de sequência, em que cada uma delas articula-se às cinco unidades temáticas: Números, Álgebra, Geometria, Grandezas e Medidas, Probabilidade e Estatística. Cada sequência corresponde à uma Trajetórias Hipotéticas de Aprendizagem (THA) que incorpora atividades de ensino organizadas a partir da indicação de objetivos para a aprendizagem (habilidades) e das hipóteses sobre o processo de aprendizagem dos estudantes. Na sequência, passamos a apresentar como o ensino de Estatística com enfoque nos gráficos e tabelas está presente na proposta do documento curricular.

\section{5 ensino de gráficos e tabelas e o Currículo Paulista de Matemática}

O ensino de Estatística com enfoque nos gráficos e tabelas está organizado na unidade temática Probabilidade e Estatística, conforme proposto pela BNCC (BRASIL, 2017).

O documento denominado Currículo Paulista (SÃO PAULO, 2019) propõe que os estudantes desenvolvam os conhecimentos primordiais para o letramento matemático, ou seja, que se apropriem da leitura e interpretação de dados e que também sejam capazes de construir uma tabela ou um gráfico, que melhor represente os dados estatísticos. 
A expectativa do documento, no que se refere à Matemática, é que a coleta e a organização de dados devem ocorrer desde os Anos Iniciais do Ensino Fundamental, a partir do planejamento de uma pesquisa de interesse comum dos estudantes. $O$ documento evidencia ainda que, para que os estudantes se tornem excelentes leitores de dados, é preciso que eles saibam mais do que elaborar e ler gráficos, ou seja, os estudantes devem aprender a explorar os recursos estatísticos e a trabalhar com a inferência para a compreensão de que dados são números com contextos.

No documento, há habilidades ${ }^{2}$ e objetos de conhecimentos ${ }^{3}$ previstos na unidade temática Probabilidade e Estatística para cada ano de escolaridade do Ensino Fundamental. Contudo, o nosso foco é o ensino de Estatística nos três primeiros anos do Ensino Fundamental (10 ao $3^{\circ}$ ano). Portanto, o Quadro 5, a seguir, evidencia o ano, o objeto de conhecimento e as habilidades para o ensino de Estatística.

Quadro 5: Habilidades e objetos de conhecimento acerca do ensino de gráficos e tabelas

\begin{tabular}{|c|c|c|}
\hline Ano & Habilidades & Objetos de Conhecimento \\
\hline \multirow[b]{2}{*}{$1^{0}$} & $\begin{array}{l}\text { (EF01MA21) Ler dados expressos em tabelas } \\
\text { e em gráficos de colunas simples. }\end{array}$ & $\begin{array}{l}\text { Leitura de tabelas e de gráficos de colunas } \\
\text { simples. }\end{array}$ \\
\hline & $\begin{array}{l}\text { (EF01MA22) Realizar pesquisa, envolvendo } \\
\text { até duas variáveis categóricas de seu } \\
\text { interesse e organizar dados por meio de } \\
\text { representações pessoais. }\end{array}$ & $\begin{array}{l}\text { Coleta e organização de informações. } \\
\text { Registros pessoais para comunicação de } \\
\text { informações coletadas. }\end{array}$ \\
\hline \multirow[t]{2}{*}{$2^{\circ}$} & $\begin{array}{l}\text { (EF02MA22) Comparar informações de } \\
\text { pesquisas apresentadas por meio de tabelas } \\
\text { de dupla entrada e em gráficos de colunas } \\
\text { simples ou barras, para melhor compreender } \\
\text { aspectos da realidade próxima. }\end{array}$ & $\begin{array}{l}\text { Coleta, classificação e representação de } \\
\text { dados em tabelas simples e de dupla entrada } \\
\text { e em gráficos de colunas. }\end{array}$ \\
\hline & $\begin{array}{l}\text { (EF02MA23) Realizar pesquisa escolhendo } \\
\text { até três variáveis categóricas de seu } \\
\text { interesse, organizando os dados coletados em } \\
\text { listas, tabelas e gráficos de colunas simples. }\end{array}$ & $\begin{array}{l}\text { Coleta, classificação e representação de } \\
\text { dados em tabelas simples e de dupla entrada } \\
\text { e em gráficos de colunas. }\end{array}$ \\
\hline $3^{0}$ & $\begin{array}{l}\text { (EF03MA26) Resolver situações-problema } \\
\text { cujo dados estão apresentados em tabelas de } \\
\text { dupla entrada, gráficos de barras ou de }\end{array}$ & $\begin{array}{l}\text { Leitura, interpretação e representação de } \\
\text { dados em tabelas de dupla entrada e gráficos } \\
\text { de barras. }\end{array}$ \\
\hline
\end{tabular}

\footnotetext{
${ }^{2}$ As habilidades apontam o que deve ser ensinado em relação aos objetos de conhecimento. Os verbos utilizados explicitam os processos cognitivos envolvidos nas habilidades, sendo estes elementos centrais para 0 desenvolvimento das competências.

${ }^{3}$ Os objetos de conhecimento ora apresentam o conceito, ora o procedimento, ou seja, um meio para que as habilidades sejam desenvolvidas. Cada objeto de conhecimento é mobilizado em uma ou mais habilidades.
} 


\begin{tabular}{|l|l|l|}
\hline colunas. & \\
\hline $\begin{array}{l}\text { (EF03MA27) Ler, interpretar e comparar } \\
\text { dados apresentados em tabelas de dupla } \\
\text { entrada, gráficos de barras ou de colunas, } \\
\text { envolvendo resultados de pesquisas } \\
\text { significativas, utilizando termos como maior e } \\
\text { menor frequência, apropriando-se desse tipo } \\
\text { de linguagem para compreender aspectos da } \\
\text { realidade sociocultural significativos. }\end{array}$ & $\begin{array}{l}\text { Leitura, interpretação e representação de } \\
\text { dados em tabelas de dupla entrada e gráficos } \\
\text { de barras. }\end{array}$ \\
\hline $\begin{array}{l}\text { (EF03MA28) Realizar pesquisa envolvendo } \\
\text { variáveis categóricas em um universo de até } \\
50 \text { elementos, organizar os dados coletados } \\
\text { utilizando listas, tabelas simples e representá- } \\
\text { los em gráficos de colunas simples, com e } \\
\text { sem uso de tecnologias digitais. }\end{array}$ & $\begin{array}{l}\text { Coleta, classificação e representação de } \\
\text { dados referentes a variáveis categóricas, por } \\
\text { meio de tabelas e gráficos. }\end{array}$ \\
\hline
\end{tabular}

Fonte: Currículo Paulista (SÃO PAULO, 2019, p. 330, 333, 336)

\section{0 ensino de Estatística nas atividades propostas para os Anos Iniciais no material do EMAI}

No Caderno do Aluno do $1^{\circ}$ ano do Ensino Fundamental, encontramos as habilidades, a seguir, em cinco sequências de atividades (6, 7, 12, 16 e 17): (EF01MA21) Ler dados expressos em tabelas e em gráficos de colunas simples e (EF01MA22) Realizar pesquisa, envolvendo até duas variáveis categóricas de seu interesse e organizar dados por meio de representações pessoais".

Na sequência 6, há duas atividades (6.1 e 6.2) que exploram a coleta, e de modo concomitante, a organização e leitura de dados em uma tabela simples, como também conduzem os estudantes no desenvolvimento de uma pesquisa de interesse comum - brinquedos, frutas favoritas, entre outros - e na representação pessoal, por meio de desenhos, registros escritos. Na sequência 7, há uma atividade (7.5) envolvendo a leitura de dados expressos em uma tabela de coluna simples. Contudo, diferentemente da sequência anterior, a comanda da atividade já apresenta os dados em uma tabela simples e incentiva que os estudantes façam uma comparação de números naturais.

Com relação à sequência 12, identificamos uma única atividade (12.3) que explora 0 desenvolvimento de uma pesquisa e a leitura dos dados representados em uma tabela. A Sequência 16 contempla uma atividade (16.3) que permite aos estudantes fazer a leitura dos 
dados de uma tabela expressos a partir da contagem de pontos de cada linha. Quanto à sequência 17, há uma atividade envolvendo a realização de uma pesquisa envolvendo as condições do tempo em três períodos distintos no dia durante uma semana.

Em se tratando das habilidades previstas para $02^{\circ}$ ano, as listadas a seguir estão presentes nas atividades de sete sequências (1, 6, 7, 10,12,15 e 17): (EF02MA22) Comparar informações de pesquisas apresentadas por meio de tabelas de dupla entrada e em gráficos de colunas simples ou barras, para melhor compreender aspectos da realidade próxima e (EF02MA23) Realizar pesquisa escolhendo até 03 (três) variáveis categóricas de seu interesse, organizando os dados coletados em listas, tabelas e gráficos de colunas simples.

Na sequência 1, há uma atividade (1.4) com a proposta de levar os estudantes a fazer um levantamento de dados acerca das idades das crianças de uma determinada turma e fazer uma organização dessas informações em uma tabela de dupla entrada. A partir disso, as crianças terão de refletir sobre algumas questões cujos dados constam na tabela, a partir dos dados coletados. Com relação à sequência 6 , a única atividade (6.3) solicita que os estudantes explorem inicialmente a tabela simples com o número de aniversariantes, número de meninas e número de meninos, depois coletem os dados faltantes e, por fim, é requerido que os estudantes respondam algumas questões referentes às informações contidas na tabela.

Quanto à sequência 7, há uma atividade (7.1) que explora o preenchimento de uma tabela simples com três variáveis - quantidade de alunos, quantidade de meninas, quantidade de meninos -, a partir dos dados levantados pelo professor responsável. Para responder às questões propostas, os estudantes devem comparar os resultados obtidos nas três ordens. No que diz respeito à sequência 10 (10.5), há uma atividade que busca a leitura e a interpretação de informações apresentadas em uma tabela de dupla entrada, a partir de um levantamento realizado pela turma a respeito de tampinhas trazidas pelos alunos ou fornecida pelo professor.

No que tange à sequência 12, existem três atividades (17.1, 17.2 e 17.3) que abordam o ensino de gráficos e tabelas. A primeira que explora a coleta de dados sobre os brinquedos preferidos pelos estudantes, como também a transcrição desses dados para uma tabela simples. Assim, ao final da atividade 12.1, é sugerido que os estudantes façam a leitura e a interpretação dos dados obtidos.

Já a segunda atividade propõe a leitura e interpretação de dados dispostos em um gráfico de colunas acerca dos brinquedos favorito da turma. Quanto à terceira atividade, é requerido que 
os estudantes façam a leitura e interpretação de informações apresentadas em um gráfico de colunas acerca de livros lidos por um grupo de quatro amigos.

Na sequência 15, a única atividade (15.1) requer dos estudantes a leitura e a interpretação de dados representados por meio de um gráfico de colunas sobre o lazer preferido da turma, em que a escala está estruturada de dois em dois (número de estudantes). Quanto à sequência 17, há uma atividade (17.3) que busca a leitura e interpretação dos dados de uma tabela acerca do registro de venda da produção de rosas em quatro dias da semana.

Em se tratando do $3^{\circ}$ ano, identificamos onze atividades envolvendo o ensino de gráficos e tabelas em seis sequências $(3,6,9,12,14$ e 16) que contemplam as seguintes habilidades: (EF03MA26) Resolver situações-problema cujo dados estão apresentados em tabelas de dupla entrada, gráficos de barras ou de colunas; (EF03MA27) Ler, interpretar e comparar dados apresentados em tabelas de dupla entrada, gráficos de barras ou de colunas, envolvendo resultados de pesquisas significativas, utilizando termos como maior e menor frequência, apropriando-se desse tipo de linguagem para compreender aspectos da realidade sociocultural significativos; e (EF03MA28) Realizar pesquisa envolvendo variáveis categóricas em um universo de até 50 elementos, organizar os dados coletados utilizando listas, tabelas simples e representálos em gráficos de colunas simples, com e sem uso de tecnologias digitais.

Na sequência 3, há duas atividades (3.4 e 3.5). A primeira envolve o desenvolvimento de uma pesquisa sobre times preferidos dos estudantes, nas quais os dados coletados devem ser organizados em tabela simples para a leitura e interpretação. Quanto à segunda atividade, além da exploração da leitura e interpretação dos números de torcedores dos times de futebol, também possibilita aos estudantes a relação com outras habilidades, tais como a resolução de problema do campo aditivo na ideia de comparação.

No que concerne à sequência 6 , são propostas duas atividades $(6.4$ e 6.5$)$ relativas ao ensino de Estatística, sendo que a primeira envolve a leitura, interpretação e comparação dos dados organizados em tabela, abrangendo resultados de pesquisas. Já a segunda atividade possibilita a leitura e interpretação de dados de um gráfico de colunas. Na sequência 9, identificamos uma atividade (9.2) que propõe a leitura e interpretação de dados sistematizados em um gráfico de colunas com informações referente à expectativa de vida, em anos, de alguns animais.

Já na sequência 12, a única atividade (12.5) permite a análise do domínio da leitura e 
interpretação de dados de tabela simples referente à distância entre cidades. Com relação à sequência 14, a atividade presente (14.1) favorece a leitura e interpretação de dados e a leitura entre os dados que necessita da competência de comparar e interpretar quantidades sistematizadas em tabela de dupla entrada.

Por fim, na sequência 16, encontramos quatro atividades (16.1. 16.2, 16.3 e 16.4). A primeira permite, além do levantamento de dados, que os estudantes percebam a similaridade das informações que foram organizadas em tipos diferentes de gráficos (em barra e em coluna), como também a contrução de um gráfico. Já as atividades 2, 3 e 4, exploram a leitura e interpretação de gráfico em barra, além de possibilitar a articulação com o campo aditivo.

\section{Análises dos Resultados}

Os cadernos do Aluno, dos três primeiros anos de escolaridade, trazem atividades que contemplam o ensino tanto de tabelas quanto de gráficos, conforme habilidades já previstas no Currículo Paulista (SÃO PAULO, 2019) e que também estão em conformidade com a BNCC (BRASIL, 2017). A tabela, a seguir, expressa a quantidade das representações.

Tabela 1: Quantidade de propostas que referentes ao Gráfico e Tabelas

\begin{tabular}{|c|c|c|c|c|c|c|c|}
\hline \multirow{2}{*}{ Ano } & \multicolumn{2}{|c|}{ Tabela } & \multicolumn{5}{c|}{ Gráfico } \\
\cline { 2 - 8 } & Simples & $\begin{array}{c}\text { Dupla } \\
\text { Entrada }\end{array}$ & $\begin{array}{c}\text { Colunas ou } \\
\text { de barras } \\
\text { verticais }\end{array}$ & $\begin{array}{c}\text { Colunas ou } \\
\text { de barras } \\
\text { horizontais }\end{array}$ & $\begin{array}{c}\text { Combinação de } \\
\text { gráficos de } \\
\text { barras verticais e } \\
\text { horizontais }\end{array}$ & $\begin{array}{c}\text { Barras } \\
\text { duplas }\end{array}$ & Setores \\
\hline $1^{\circ}$ & 6 & 0 & 0 & 0 & 0 & 0 & 0 \\
\hline $2^{\circ}$ & 3 & 3 & 3 & 0 & 0 & 0 & 0 \\
\hline $3^{\circ}$ & 4 & 1 & 2 & 3 & 1 & 0 & 0 \\
\hline
\end{tabular}

Fonte: Dados da Pesquisa

Como podemos observar na Tabela 1, o Caderno do Aluno do $1^{\circ}$ ano apresenta 6 atividades envolvendo 0 ensino de tabela. No $2^{\circ}$ ano, traz 9 atividades, sendo 6 envolvendo 0 ensino de tabelas e 3 contemplando gráficos. Já o $3^{\circ}$ ano, apresenta 11 atividades, das quais 5 envolvem tabelas e 6 delas abrangem gráficos.

As atividades elaboradas avançam ano a ano dos três primeiros anos do Ensino Fundamental, pois inicialmente trazem como proposta para $01^{\circ}$ ano a leitura de dados 
apresentados em tabelas simples e a realização de uma pesquisa de interesse comum de até duas variáveis (Figura 1). Depois, no $2^{\circ}$ ano, há a preservação do trabalho com tabela simples, mas traz a progressão para a tabela de dupla entrada e o trabalho com gráficos de colunas simples e de barras e o levantamento de dados com até três variáveis categóricas (Figura 2) e por fim, no $3^{0}$ ano, as propostas avançam na leitura e na comparação de dados expressos em gráficos de barras e de colunas e há uma manutenção no trato com tabelas simples e de dupla entrada.

Figura 1: Exemplo de atividade do $1^{\circ}$ ano explorando tabela simples e a realização de pesquisa



Fonte: Caderno do Aluno — EMAI, v. 1 (SÃO PAULO, 2020, p. 33) 
Figura 2: Exemplo de atividade do $2^{\circ}$ ano explorando três variáveis

\begin{tabular}{|c|c|c|c|}
\hline \multicolumn{4}{|c|}{ CONTAGENS E CALCULADORA } \\
\hline \multicolumn{4}{|c|}{$\begin{array}{l}\text { 1. REGISTRE, NA TABELA ABAIXO, AS INFORMAÇOES OBTIDAS POR SEU(SUA) } \\
\text { PROFESSOR(A) NA SECRETARIA DA ESCOLA: }\end{array}$} \\
\hline \multicolumn{4}{|c|}{ NÚMERO DE ALUNOS DOS ANOS INICIAIS DA NOSSA ESCOLA } \\
\hline TURMA & $\begin{array}{l}\text { QUANTIDADE } \\
\text { DE ALUNOS }\end{array}$ & $\begin{array}{l}\text { QUANTIDADE } \\
\text { DE MENINAS }\end{array}$ & $\begin{array}{l}\text { QUANTIDADE } \\
\text { DE MENINOS }\end{array}$ \\
\hline \multicolumn{4}{|l|}{ PRIMEIROS ANOS } \\
\hline \multicolumn{4}{|l|}{ SEGUNDOS ANOS } \\
\hline \multicolumn{4}{|l|}{ TERCEIROS ANOS } \\
\hline \multicolumn{4}{|l|}{ QUARTOS ANOS } \\
\hline \multicolumn{4}{|l|}{ QUINTOS ANOS } \\
\hline \multicolumn{4}{|l|}{ TOTAL } \\
\hline \multicolumn{4}{|l|}{ Fonte: Secretarla da Escola } \\
\hline \multicolumn{4}{|c|}{ 2. RESPONDA AS QUESTOES: } \\
\hline \multicolumn{4}{|c|}{ A. A TABELA TEM UM TÍTULO. O QUE ELE INFORMA? } \\
\hline \multicolumn{4}{|c|}{ B. QUANTOS ALUNOS HÁ NOS PRIMEIROS ANOS? } \\
\hline \multicolumn{4}{|c|}{ C. QUANTOS ALUNOS HÁ NOS SEGUNDOS ANOS? } \\
\hline \multicolumn{4}{|c|}{ D. HA MAIS QUE 100 ALUNOS NOS TERCEIROS ANOS? } \\
\hline \multicolumn{4}{|c|}{ E. E NOS QUARTOS ANOS, HÁ MENOS DE 90 ALUNOS? } \\
\hline \multicolumn{4}{|c|}{ F. QUANTOS ALUNOS HA NOS QUINTOS ANOS? } \\
\hline \multicolumn{4}{|c|}{ G. QUAL DESSAS TURMAS É A MAIS NUMEROSA? } \\
\hline \multicolumn{4}{|c|}{ H. HÁ TURMAS COM A MESMA QUANTIDADE DE ALUNOS? } \\
\hline \multicolumn{4}{|c|}{ I. HA MAIS MENINAS OU MENINOS NA ESCOLA? } \\
\hline \multicolumn{4}{|c|}{ J. QUAL O TOTAL DE ALUNOS NA ESCOLA? } \\
\hline
\end{tabular}

Fonte: Caderno do Aluno - EMAl, v. 1 (SÃO PAULO, 2020, p. 43)

No entanto, não notamos nas propostas do Caderno do $1^{\circ}$ ano, a introdução da leitura de gráficos de colunas simples, conforme já prescrito no Currículo Paulista (SÃO PAULO, 2019). Compreendemos que desde $01^{\circ}$ ano do Ensino Fundamental os estudantes já são capazes de construir representações com escalas unitárias.

No $2^{\circ}$ ano, as atividades envolvendo gráficos privilegiam mais a leitura e a interpretação de dados já prontos (Figura 3). Nota-se também que as atividades que envolvem pesquisas, as propostas estão relacionadas à organização dos dados somente em tabelas (Figura 4). 
Figura 3: Atividade do $2^{\circ}$ ano que explora um gráfico já construído

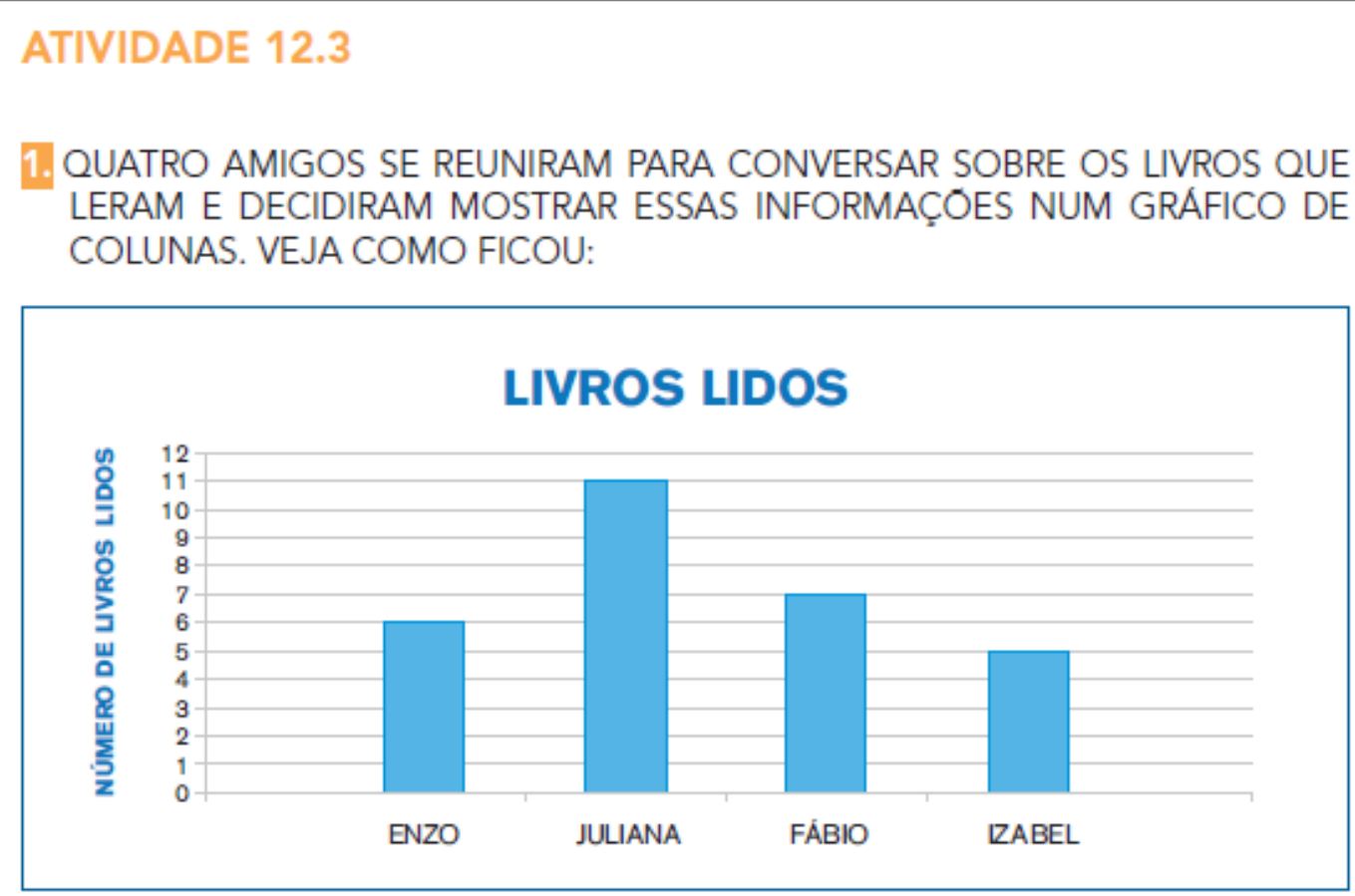

Fonte: dados obtidos por Jullana

2. RESPONDA:

A. QUAIS OS NOMES DESSES AMIGOS?

B. QUANTOS LIVROS ENZO LEU?

C. QUEM LEU MAIS LIVROS?

D. QUE MENINA LEU MAIS LIVROS?

E. QUANTOS LIVROS FÁBIO LEU A MAIS QUE IZABEL?

F. QUEM LEU MAIS DE 6 LIVROS?

Fonte: Caderno do Aluno - EMAl, v. 1 (SÃO PAULO, 2020, p. 74) 
Figura 4: Exemplo de atividade do $1^{\circ}$ ano que envolve a realização de pesquisas e construção de tabelas

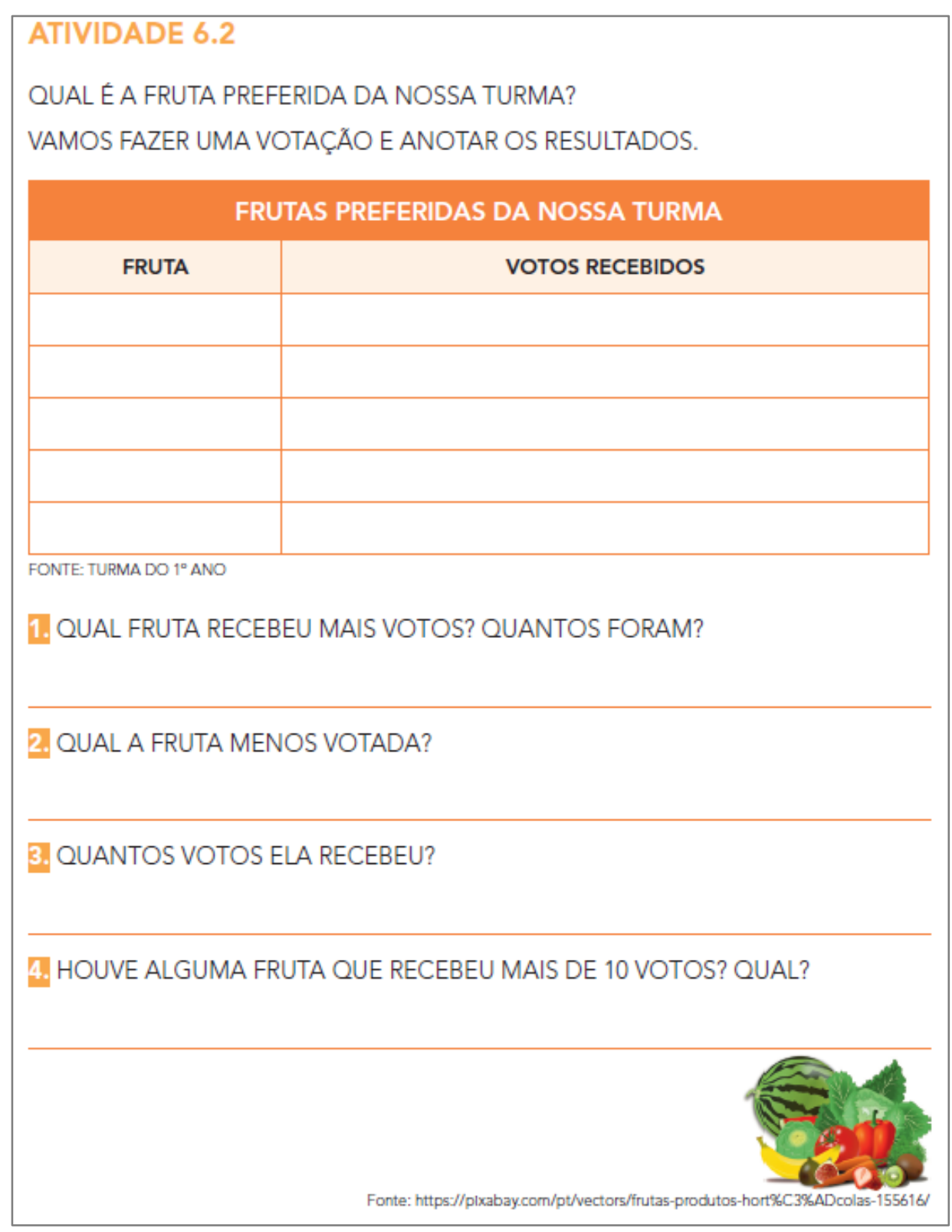

Fonte: Caderno do Aluno - EMAI, v. 1 (SÃO PAULO, 2020, p. 33)

No $3^{\circ}$ ano, embora as atividades contemplem questões que incentivem 0 raciocínio estatístico, há apenas uma questão propondo a produção de um texto sintetizando os resultados. Além disso, notamos somente uma única questão, em uma das atividades do $3^{\circ}$ ano, que requer a construção de um gráfico (Figura 5) a partir de um levantamento.

É importante destacar que essa mesma atividade do $3^{\circ}$ ano traz um comparativo entre 0 gráfico de barra dupla e barra horizontal, buscando que os estudantes compreendam que as informações contidas em ambos os gráficos são idênticas, contudo, apenas representadas em gráficos de tipos diferentes. 
Figura 5: Exemplo de atividade do $3^{\circ}$ ano que traz uma comparação entre gráficos de barras horizontal e vertical

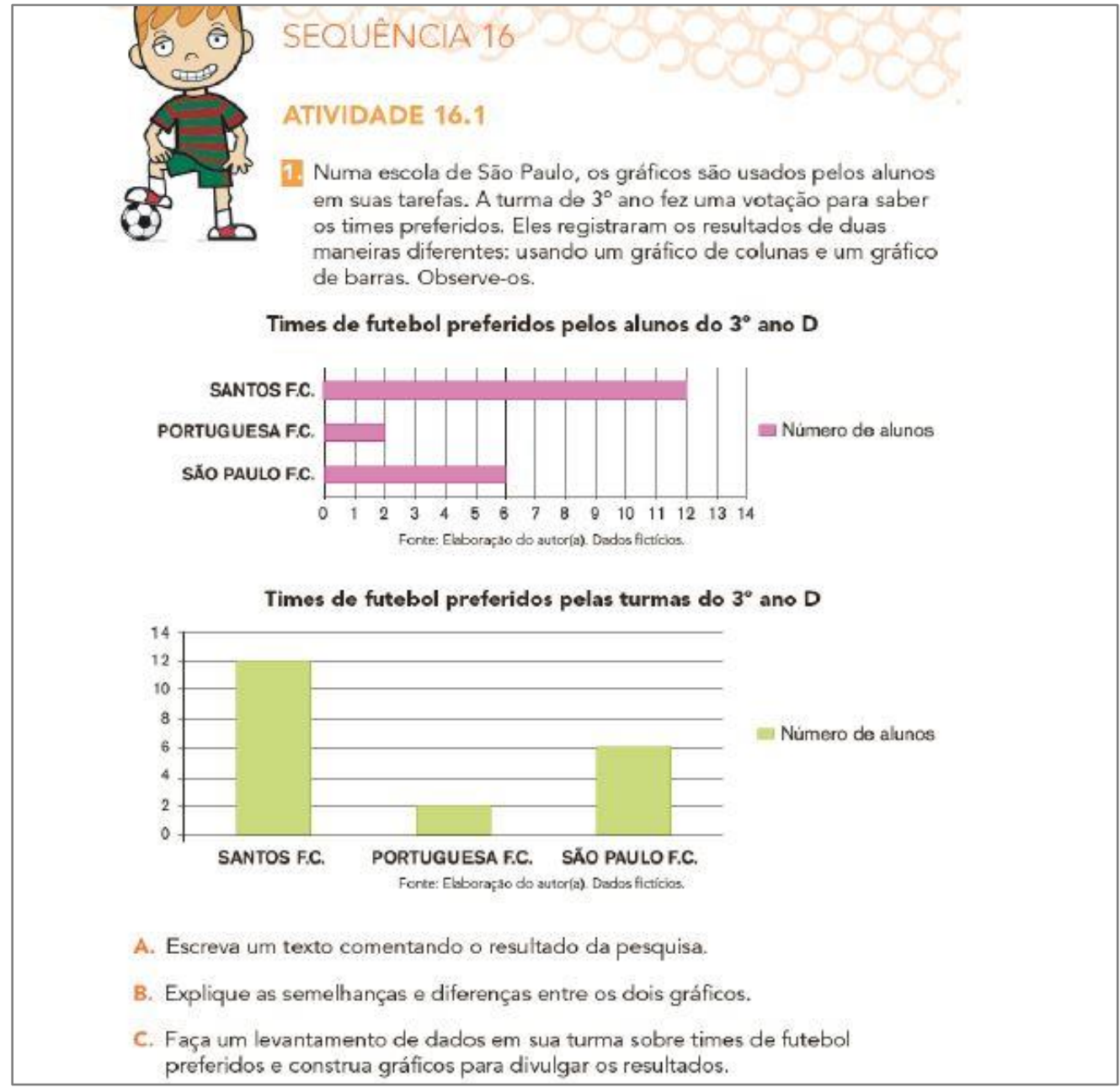

Fonte: Caderno do Aluno - EMAI, v. 1 (SÃO PAULO, 2020, p. 87)

No $3^{\circ}$ ano, não identificamos atividades que explorem o gráfico de linhas e registros pictóricos, conforme prescrito no Currículo Paulista (SÃO PAULO, 2019). Todas as atividades do $2^{\circ}$ e $3^{\circ}$ ano predominam o uso de gráficos de colunas ou de barras.

A partir da análise realizada, constatamos que uma das ideias fundamentais da Matemática, a representação, está presente nos Cadernos, desde $01^{\circ}$ ano, pois permite que os estudantes possam apoiar-se nas representações icônicas - figuras, esquemas, entre outros -, por exemplo, o número 3 pode ser representado por variadas formas: pelo desenho de três frutas; três pontos em uma linha, como também na linguagem escrita.

Observamos que somente três atividades do $2^{\circ}$ ano, envolvendo tabelas - que podem ser representadas pela Figura 6 -, solicitam que os estudantes explorem o título e a fonte da tabela, para desvendar o contexto, a qualidade e fidelidade dos dados. Além disso, apenas poucas indicam a fonte. 
Figura 6: Exemplo de atividade do $2^{\circ}$ ano que explora o título e indica fonte

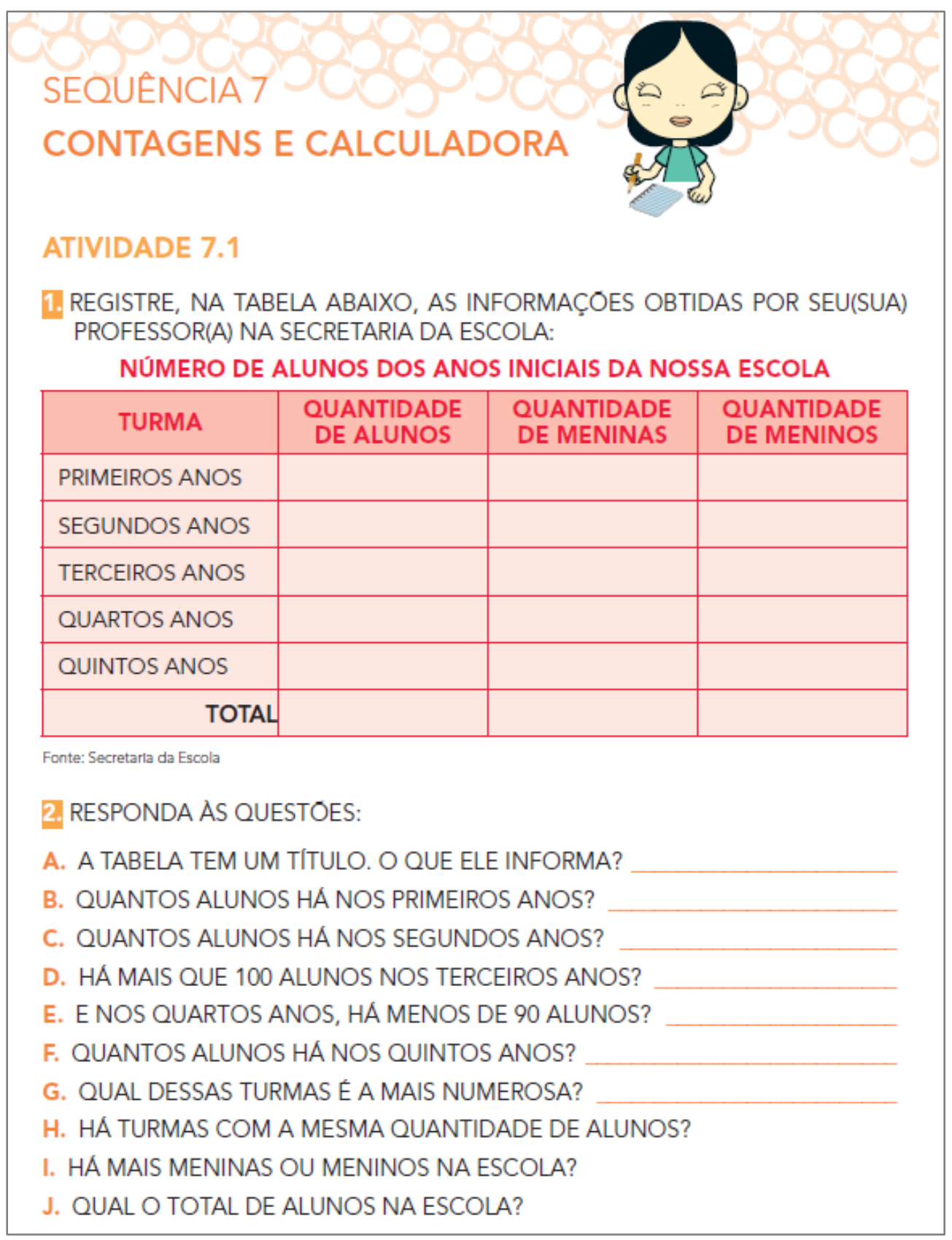

Fonte: Caderno do Aluno - EMAl, v. 1 (SÃO PAULO, 2020, p. 43)

As atividades do Caderno do $2^{\circ}$ e $3^{\circ}$ ano levam os estudantes para a compreensão dos dados expressados e as suas diferenças nos valores entre as linhas da tabela. Há atividades (Figura 7) em que os estudantes podem comparar os dados a longo prazo e compreender a razão da diferença entre os dados, considerando os aspectos ambientais. 
Figura 7: Exemplo de atividade do $1^{\circ}$ ano que envolve a comparação de dados a longo prazo

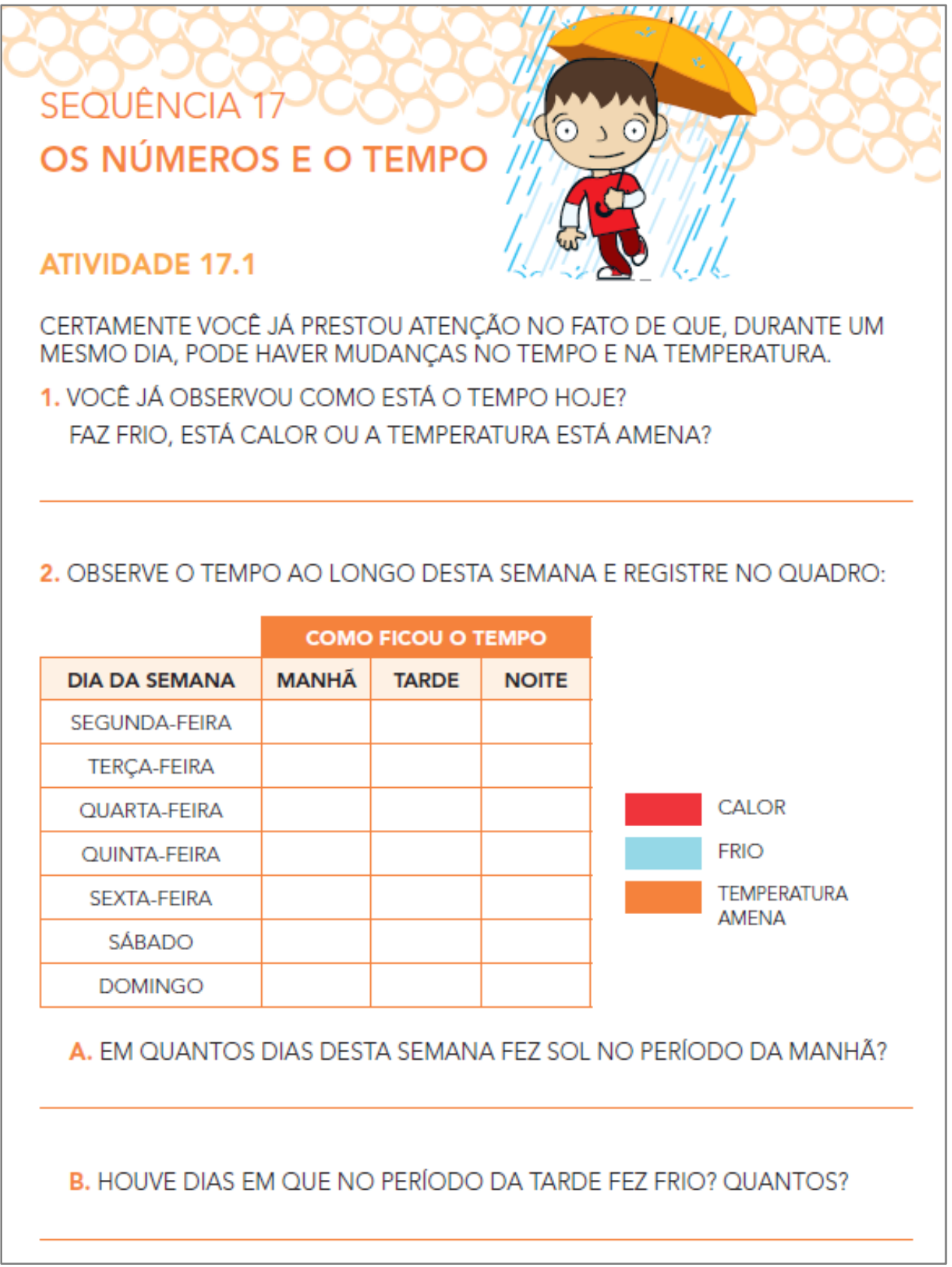

Fonte: Caderno do Aluno - EMAl, v. 1 (SÃO PAULO, 2020, p. 85)

As análises realizadas permitem evidenciar que as atividades presentes nos Cadernos dos três anos possibilitam o desenvolvimento do raciocínio estatístico, de modo que as propostas sugerem a realização de pesquisas sobre a preferência dos estudantes em relação às frutas, brinquedos, entre outros; a organização, registro e a comunicação dos dados levantados; a leitura e comparação dos resultados registrados em tabelas ou em gráficos. No $3^{\circ}$ ano, algumas atividades presentes incentivam o desenvolvimento do pensamento estatístico, pois permitem que os estudantes possam analisar as informações estatísticas e a comunicá-las por meio de registros 
escritos.

Nas atividades apresentadas do $1^{\circ}$ ano, relativas ao ensino de gráficos e tabelas, observamos claramente o primeiro nível de leitura propostos por Curcio (1987): a leitura literal de dados. As questões contidas nas sequências de atividades do Caderno do $2^{\circ}$ e $3^{\circ}$ ano, envolvendo gráficos, estão no primeiro e segundo nível descrito por Curcio (1987), pois algumas delas, em uma mesma atividade, requerem apenas a leitura literal do gráfico e outras exigem a leitura entre os dados, ou seja, uma interpretação maior sobre as informações representadas.

Constatamos, ainda, que nas atividades dos Cadernos há a denominação quadro e tabela para o mesmo tipo de representação gráfica, o que consideramos um equívoco, pois a tabela representa os dados quantitativos e não apresenta bordas laterais. Já o quadro apresenta dados textuais e bordas ${ }^{4}$. A Figura 8 adiante ilustra tal constatação.

Figura 8: Exemplo de atividade do $2^{\circ}$ ano que apresenta uma tabela com bordas laterais

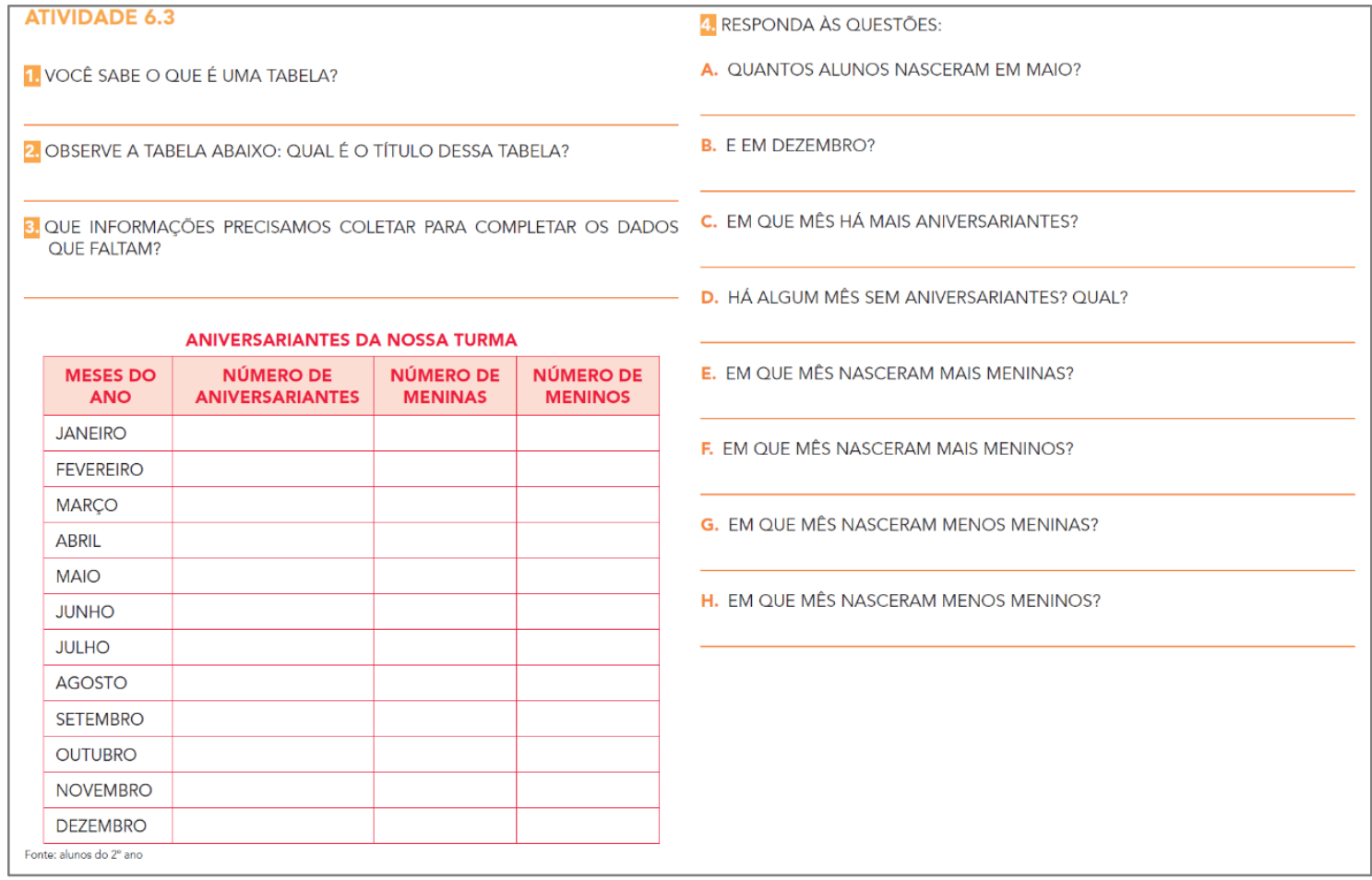

Fonte: Caderno do Aluno - EMAI, v. 1 (SÃO PAULO, 2020, p. 40-41)

Convém destacar, ainda, que essa é a única atividade nos Cadernos, referentes aos três anos de escolaridade, que apresenta uma única questão que permite os estudantes discutirem 0

\footnotetext{
${ }^{4} \mathrm{~A}$ estrutura da tabela é constituída de traços (retas perpendiculares) e é delimitada em sua parte superior e na parte inferior por traços horizontais paralelos. Não delimitar (fechar) com traços verticais as laterais direita e esquerda (BRITO, CHOI e ALMEDIDA, 2014).
} 
conceito de tabela.

Para finalizar, observamos que a maioria das questões apresentadas nas atividades dos Cadernos dos três anos não apresentam potencial comunicativo, embora as habilidades propostas nas atividades apresentem os verbos de ações ler e interpretar. Entendemos, que faltaram propostas do tipo: registre ou descreva oralmente como você pensou ou descreva oralmente 0 que você observou.

Esses tipos de comandas permitem aos estudantes o desenvolvimento da comunicação de um pensamento estatístico. Seu registro em um texto e análise posterior permite avanços no pensamento estatístico dos estudantes.

\section{Considerações Finais}

Ao analisarmos os Cadernos do Aluno no material EMAI, no que concerne ao trabalho com gráficos e tabelas nos três primeiros anos do Ensino Fundamental, percebemos que as atividades propostas estão todas de acordo com as habilidades do Currículo Paulista (SÃO PAULO, 2019) e este, por sua vez, está alinhado com a BNCC (2017).

As atividades analisadas contribuem para a promoção do desenvolvimento da Literacia Estatística por encaminhar os estudantes na compreensão das informações estatísticas, na organização dos dados, por meio de pesquisas, e na representação de tabelas. Contudo, a aquisição da Literacia Estatística requer outras habilidades que as atividades não incentivam tanto - a capacidade de argumentar, a construção e representação de gráficos e tabelas, a apropriação do vocabulário estatístico e a competência de produzir textos acerca de suas interpretações.

Compreendemos, ainda, que a aquisição de habilidades correlatas a Literacia Estatística também se dá com o apoio do professor, na sua relação com o estudante, mediada pelo uso de materiais curriculares.

Verificamos, ainda, que muito embora as propostas das atividades não estejam voltadas, em sua maioria, para a construção de tabelas e gráficos, todas situações apresentadas estão direcionadas às pesquisas que envolvem o contexto familiar dos estudantes, pois abordam as frutas, brinquedos e times preferidos, entre outros. A nosso ver, são conjunturas que despertam 0 interesse comum dos estudantes e permitem que eles possam tecer argumentos sobre o que interpretam e o que foi registrado nos levantamentos realizados. 
Outro aspecto que é possível observar nas atividades propostas, é que elas permitem que os estudantes dos três primeiros anos do Ensino Fundamental consigam identificar, interpretar e ler os dados. Porém, observamos que não são apresentadas atividades para que os estudantes possam ir além - empregando ideias estatísticas e conferindo um significado à informação estatística.

Por fim, não podemos deixar de considerar que a proposta curricular apresentada nos Cadernos do Aluno do material EMAI foram se ampliando e se tornado mais complexas, ao longo das propostas analisadas, mas como já foi dito, faltaram alguns aspectos para que os estudantes possam finalmente adquirir a Literacia Estatística.

\section{Referências}

BARDIN, Laurence. Análise de conteúdo. Tradução de Luís Augusto Pinheiro. São Paulo: Edições 70, 2016.

BATANERO, Carmen; ARTEAGA, Pedro; CONTRERAS, José Miguel. El currículo de Estadística em la enseñanza obligatoria. Em Teia, Recife, v. 2, n. 2, p. 1-20, maio/ago. 2011.

BRASIL. Ministério da Educação. Secretaria da Educação Básica. Base Nacional Comum Curricular. Brasília: MEC/SEB, 2017.

BRITO, Gisele Ferreira; CHOI, Vania Picanço; ALMEIDA, Andreia. (Org.). Manual ABNT: regras gerais de estilo e formatação de trabalhos acadêmicos. 4. ed. rev. São Paulo: FECAP, 2014.

CURCIO, Frances. Comprehension of mathematical relationships expressed in graphs. Journal for Research in Mathematics Education, v. 18, n. 5, p. 382-393, nov. 1987.

CURCIO, Frances. Developing graph comprehension: Elementary and Middle School activities. Reston: NCTM, 1989.

CURI, Edda. (Coord.). 0 ensino de Matemática em questão: apontamentos para discussão e implementação do Currículo da Cidade. São Paulo: SME/COPED, 2019.

DelMAS, Robert C. Statistical literacy, reasoning and learning: a commentary. Journal of Statistics Education, v. 10, n. 3, p. 1-11, 2002.

FLORES, Claudia Regina, MORETTI, Méricles Thadeu. O funcionamento cognitivo e semiótico das representações gráficas: ponto de análise para a aprendizagem matemática. In: REUNIÃO ANUAL DA ASSOCIAÇÃO NACIONAL DE PÓS-GRADUAÇÃO E PESQUISA EM EDUCAÇÃO, 28, Caxambu, 2005. Anais da $28^{\mathrm{a}}$ Reunião da ANPEd. Caxambu: ANPEd, 2005, p. 1-13.

GAL, Iddo. Adult statistical literacy: meanings, components, responsabilities. International Statistical Review, v. 70, n. 1, p. 1-25, apr. 2002. 
JACOBINI, Otávio Roberto; WODEWOTZKI, Maria Lúcia Lorenzetti; CAMPOS, Celso Ribeiro; FERREIRA, Denise Helena Lombardo. Temas contemporâneos nas aulas de Estatística: um caminho para combinar aprendizagem e reflexões políticas. In: LOPES, Celi Aparecida Espasandin; COUTINHO, Cileda de Queiroz Silva; ALMOULOUD; Saddo Ag. (Org.) Estudos e reflexões em Educação Estatística. Campinas: Mercado de Letras, 2010, p. 65-83.

KEMP, Marian. Developing critical numeracy at the tertiary level. 2005. 288f. Thesis (Docyorate of Education) - Murdoch University. Western (Australia)

LOPES, Celi Aparecida Espasandin. Literacia estatística e INAF 2002. In: FONSECA, Maria da Conceição Ferreira Reis. (Org.). Letramento no Brasil: habilidades matemáticas. São Paulo: Global, 2004, p. 187-197.

LOPES, Celi Aparecida Espasandin. 0 ensino de Estatística e da Probabilidade na Educação Básica e a formação de professores. Caderno Cedes, Campinas, v. 27, n. 74, p. 57-73, jan./abr. 2008.

SACRISTÁN, José Gimeno. O que significa o currículo? In: SACRISTÁN, José Gimeno. (Org.). Saberes e incertezas sobre o currículo. Tradução: Alexandra Salvaterra. Porto Alegre: Penso, 2013, p. 16-35.

SÃO PAULO (Estado). Secretaria de Estado da Educação. Centro de Educação Infantil e Anos Iniciais do Ensino Fundamental. EMAI \& Ler e Escrever: Ensino Fundamental, $1^{\circ}$ ano, v. 1, Caderno do Aluno. São Paulo: SEE/CEFAl, 2020.

SÃO PAULO (Estado). Secretaria de Estado da Educação. Centro de Educação Infantil e Anos Iniciais do Ensino Fundamental. EMAI \& Ler e Escrever: Ensino Fundamental, $2^{\circ}$ ano, v. 1, Caderno do Aluno. São Paulo: SEE/CEFAl, 2020.

SÃO PAULO (Estado). Secretaria de Estado da Educação. Centro de Educação Infantil e Anos Iniciais do Ensino Fundamental. EMAI \& Ler e Escrever: Ensino Fundamental, $3^{\circ}$ ano, v. 1, Caderno do Aluno. São Paulo: SEE/CEFAI, 2020.

SÃO PAULO (Estado). Secretaria de Estado da Educação. Currículo Paulista. São Paulo: SEE, 2019. 